\title{
O ESTUDO DA PERFORMANCE MUSICAL E O SEU CARÁTER SOCIAL
}

\section{THE STUDY OF MUSICAL PERFORMANCE AND ITS SOCIAL CHARACTER}

\author{
Marcus Almeida \\ Universidade Estadual de Campinas \\ mva.guit@outlook.com
}

\section{Resumo}

$\bigcirc$ presente artigo oferece alternativas para o estudo da performance musical. A partir da constatação feita por Nicholas Cook de que toda performance possui uma dimensão social, a etnografia é apresentada como metodologia para pesquisa em Música. Então, são apresentados autores que compreendem a performance como um fenômeno social e, desse modo, estabelecem uma relação entre a pesquisa musical e as Ciências Sociais, particularmente a Antropologia. Com o objetivo de estabelecer diretrizes para o pesquisador, abordamse os conceitos da Antropologia Musical de Anthony Seeger, da Antropologia da Performance de Richard Schechner e Victor Turner, e, por último, o conceito de Musicar de Christopher Small.

Palavras-chave: performance; antropologia musical; antropologia da performance; Musicar.

\section{Abstract}

This article offers alternatives to the study of musical performance. From the observation made by Nicholas Cook that every performance has a social dimension, ethnography is presented as a methodology for musical research. Then, it is showed some authors who understand the performance as a social phenomenon and establish a link between musical research and the social sciences, particularly anthropology. In order to establish guidelines for the research, it is discussed the concepts of "Musical Anthropology" (Anthony Seeger), "Anthropology of Performance" (Richard Schechner and Victor Turner), and, the concept of "music", by Christopher Small. 
Keywords: musical performance; musical anthropology; anthropology of performance; Musicking.

\section{Performance Musical: um fenômeno irredutivelmente social}

estudo da performance em Música, conforme observou Cook (COOK, 2006), esteve, durante muito tempo, limitado à ideia de que o trabalho do instrumentista era executar as orientações presentes na partitura com o máximo de precisão. Desse modo, o intérprete instrumentista deveria debruçar-se em seu instrumento, aprimorando ao máximo o controle sobre esse, a fim de, ao receber uma partitura, ser capaz de compreender todas as informações ali presentes e executálas da maneira mais precisa possivel.

Seguindo essa linha de pensamento, Schoenberg teria dito que "O performer, a despeito de sua intolerável arrogância, é totalmente desnecessário, exceto pelo fato de que as suas interpretações tornam a música compreensivel para uma plateia cuja infelicidade é não conseguir ler esta música impressa" (NEULIN, 1980, p. 164). Independentemente do contexto em que teria sido feita, essa afirmação é emblemática pelo fato de representar o ponto de vista de diversos estudiosos da Música. Não é difícil encontrar opiniões que vão ao encontro dessa linha de pensamento, colocando o intérprete a serviço do compositor. Nesse sentido, Cook acrescenta: "a ideia de que a performance é essencialmente reprodução e, consequentemente, uma atividade subordinada, senão redundante, está inserida na nossa própria linguagem" (COOK, 2006, p. 6). Em sua argumentação, o autor coloca:

É tentador dizer que tudo isso é bobagem e que o que é necessário é simplesmente um senso adequado de equilibrio e respeito mútuo entre os músicos. Mas isso é ignorar a influência do que chamo de gramática da performance: um paradigma conceitual que vê o processo como sendo subordinado ao produto. E o fato deste paradigma estar profundamente enraizado na musicologia não surpreende: em sua origem, no século XIX, esta disciplina espelhou-se no status e nos métodos da filologia e da literatura, de modo que o estudo de textos musicais acabou modelando-se 
no estudo de textos literários. Entretanto, e não importa o quanto isso seja implausivel, somos levados a pensar a música como pensamos a poesia, como uma prática cultural centrada na contemplação silenciosa do texto escrito, com a performance (tal como a leitura de poesias em público) servindo como um tipo de suplemento. Além disso, a orientação tradicional da musicologia pautada na reconstrução e disseminação de textos de autoridade refletiu uma preocupação básica com as obras musicais enquanto obras dos seus compositores, compreendendoas como mensagens a serem transmitidas do compositor ao público, tão fielmente quanto possível (COOK, 2006, p. 7).

Em contraponto a essa visão, Cook propõe uma abordagem onde a ênfase esteja no processo e não no produto. Em suas palavras, a "dimensão performática" da música deveria se sobrepor. Assim, o "processo" (a performance) não deveria ser visto como algo subordinado ao "produto" (a obra musical). Seguindo essa linha, conclui: "compreender música enquanto performance significa vêla como um fenômeno irredutivelmente social, mesmo quando apenas um indivíduo está envolvido" (COOK, 2006, p. 11, grifo nosso). Aqui, - autor procura ampliar a visão sobre o que é música enquanto performance, transcendendo o universo estritamente sonoro. Para isso, enfatiza a "dimensão irredutivelmente social" da performance musical. No entanto, e faz-se necessário esclarecer, Cook não despreza o papel do compositor, e sublinha: "enfatizar a dimensão irredutivelmente social da performance musical não é negar o papel da obra do compositor, mas sim constatar as implicações para o nosso entendimento do que vem a ser esta obra" (Idem). Em suma, o que o autor pretende enfatizar é que Música é uma arte de performance e que, para pensar nela como tal, devemos refletir a maneira como a conceituamos. Nesse contexto, é importante acrescentar que uma análise musical focada unicamente nas relações entre notas e ritmos não seria suficiente. Compreender música enquanto performance transcende o universo da partitura e a relação que o intérprete estabelece com a obra. Assim, o que se busca é uma alternativa para o estudo da Música enquanto performance. Para Cook, a vertente dos estudos contemporâneos da performance que melhor esclarece a relação entre o pesquisador e o fenômeno pesquisado é a etnomusicologia: 
A etnomusicologia, desde o início, se distanciou do modelo de observação impessoal e síntese que caracterizava o campo de estudo que havia precedido, a musicologia comparativa. Ao invés disso, a etnomusicologia enfatizou a necessidade dos trabalhos de campo, entendidos como um prolongado período de residência junto à cultura em questão. Durante este período, as práticas musicais são observadas no seu contexto cultural, adquirindo-se uma compreensão da visão local. [...]

Resumindo, este trabalho de campo enfatiza a participação pessoal na geração de significado em performance que é a musica (COOK, 2006, p. 13. Grifo no original).

Com esse diagnóstico, Cook aproxima os estudos musicológicos das Ciências Sociais, ou, para ser mais preciso, o autor aproxima o estudo da performance musical da Antropologia. Em artigo mais recente (COOK, 2008), o autor coloca a maneira como enxerga as transformações pelas quais a Musicologia passou nas últimas décadas do século XX, em direção ao entendimento da música em seus múltiplos contextos culturais, abrangendo a produção, a performance, a recepção e todas as outras atividades em virtude da qual a música é construida como uma prática cultural significativa. Nesse sentido, o autor observa: "Historicamente, a musicologia tem se preocupado, de uma maneira ou de outra, com o entendimento da música nesses contextos, mas o que foi inovador em relação à Musicologia, anteriormente reconhecido como "Novo", foi se preocupar explicitamente com o ato de interpretar e com os valores inerentes a isso" (COOK, 2008, p. 49).

Em outras palavras, para Cook, a novidade dos estudos etnomusicológicos mais recentes está em se preocupar com as questões relativas à interpretação musical, o que aponta para a aproximação dos estudos da prática musical (da performance) à Etnomusicologia.

De maneira geral, é possivel dizer que a área do conhecimento na qual a etnomusicologia se encontra compreende em 50\% Musicologia e 50\% Antropologia. Segundo Tiago de Oliveira Pinto, a Etnomusicologia é uma: 
disciplina que durante longo tempo foi entendida como de natureza hibrida, ou seja, pertencente à musicologia quanto a seus conteúdos e à antropologia quando se trata de seus métodos de pesquisa. independente deste "dilema", a etnomusicologia estabeleceu-se com centros de estudos e de pesquisa nas principais universidades americanas e europeias, firmando-se, cada vez mais, com expressão própria também no Brasil (PINTO, 2001, p. 223).

Sendo a etnomusicologia a área proposta por Cook para - estudo da performance musical, vale a pena reforçar o básico: "o que faz um etnógrafo?". Para essa resposta, Geertz (CEERTZ, 2008) é direto: "ele escreve". Sendo mais preciso, o próprio Geertz acrescenta: "O etnógrafo 'inscreve' o discurso social: ele o anota. Ao fazê-lo, ele - transforma de acontecimento passado, que existe em seu próprio momento de ocorrência, em um relato, que existe em sua inscrição e que pode ser consultado novamente" (CEERTZ, 2008, p. 14, grifos no original).

Seguindo a trilha da etnomusicologia, Geertz esclarece o que chamou de "descrição densa" do fenômeno observado. Com isso, ele propõe uma "ciência interpretativa, à procura de significado" (CEERTZ, 2008, p. 04). Assim,

[...] O que o etnógrafo enfrenta, de fato [...], é uma multiplicidade de estruturas conceptuais complexas, muitas delas sobrepostas ou amarradas umas às outras, que são simultaneamente estranhas, irregulares e inexplícitas, e que tem que, de alguma forma, primeiro apreender e depois apresentar. E isso é verdade em todos os níveis de atividade do seu trabalho de campo, mesmo o mais rotineiro: entrevistar informantes, observar rituais, deduzir os termos de parentesco, traçar as linhas de propriedade, fazer o censo doméstico... escrever seu diário (CEERTZ, 2008, p. 7). 


\section{Antropologia Musical}

Retomando a discussão levantada por Cook, que propõe a etnomusicologia como alternativa para o estudo da performance, a Antropologia Musical apresentada por Anthony Seeger aparece como um caminho viável para compreender a Música nesse contexto. Oriundo de uma família de músicos e musicólogos, Anthony Seeger possui uma importante bibliografia no campo da Antropologia Social, com destaque para as artes e, especialmente, a Música. Em seus trabalhos, Seeger faz questão de realçar a diferença entre uma antropologia da música e uma antropologia musical. Segundo o antropólogo, enquanto a antropologia da música traz para o estudo da música os conceitos, métodos e preocupações da antropologia e, com isso, olharia para a música como uma parte da cultura e da vida social, uma antropologia musical olha para a maneira como uma performance musical cria muitos aspectos da cultura e da vida social. Para Seeger, em vez de estudar música na cultura, uma antropologia musical deve estudar a vida social como uma performance (SEECER, 2004, p. xiii). Com base nisso, coloca:

Música é muito mais do que apenas sons capturados por um gravador. Música é a intenção de fazer algo denominado música (ou estruturado de maneira parecida com o que nós denominamos música) em oposição a outros tipos de sons. É a habilidade de formular sons aceitos por membros de uma sociedade como música (ou seja lá como eles denominam esses sons). Música é a construção e o uso de instrumentos para produzir som. É o uso do corpo para produzir e acompanhar os sons. Música é a emoção que acompanha a produção, a apreciação e a participação em uma performance. Música é também, obviamente, o próprio som depois que ele é produzido. Ainda, é a intenção, tanto quanto a realização; é a emoção e valor tanto quanto estrutura e forma (SEECER, 2004, p. xiv. Tradução nossa. Grifo no original).

É importante notar que essa definição de Música remete a algo mais amplo do que se costuma estudar nos departamentos de Música. Ao afirmar que Música é muito mais do que apenas sons, mas é a intenção tanto quanto a realização, e a emoção tanto quanto estrutura e forma, Seeger abre espaço para diferentes análises do fenômeno musical. 
Seguindo essa definição, o autor acrescenta todo tipo de situação que, direta ou indiretamente, se relaciona com o que "nós denominamos música". Sob esse ponto de vista, uma performance musical sofre interferência de diversos elementos, desde a produção de instrumentos, passando pelo uso do corpo para produzir e acompanhar os sons, até a participação em uma performance musical, seja como músico ou ouvinte. Desse modo, Seeger retira dos músicos a exclusividade do fazer musical, e acrescenta outros agentes. Nessa perspectiva, pensar, por exemplo, em uma apresentação de um grupo de jazz em um bar é tornar relevante as palmas que a plateia faz quando o instrumentista termina - seu solo. É considerar importante para a performance o cuidado que o proprietário tem (ou não) em manter o piano afinado. É, também, admitir que a maneira como a garçonete recebe os músicos quando eles chegam para passar o som antes de começar a apresentação faz diferença para essa música.

Nesse momento, é possivel estabelecer uma conexão entre Seeger e Cook. Ao olhar para a Música em uma perspectiva mais ampla, considerando-a "muito mais do que apenas sons", Seeger, não apenas propõe uma Antropologia Musical, como também fornece elementos para que a performance seja compreendida enquanto um fenômeno "irredutivelmente social". Nesse sentido, algumas pistas são apresentadas. Segundo Seeger (SEECER, 2008, p. 238), certas características seriam comuns a todas as performances musicais. Como exemplo, ele cita 0 fato de os músicos passarem por um longo treinamento em alguma tradição musical. Além disso, a música que esses músicos executam deve ser "significante o suficiente para justificar a eles e à audiência o tempo, o dinheiro, a comida ou a energia utilizada no evento" (idem). Seguindo esse raciocínio, Seeger conclui que, independentemente da cultura ou da tradição musical, deve existir um tipo de interação entre os performers e a plateia: "eles se comunicam entre si por meio de sinais para coordenar a performance" (idem). Para Seeger, a base da etnografia da música é formada pela descrição desses eventos, onde o fato de que sempre existirá uma próxima vez aponta para a tradição, e o fato de que a próxima vez nunca será igual à anterior para a mudança. Ao constatar a existência de uma interação entre performers e plateia, Seeger - assim como Cook - sinaliza para a necessidade de se entender a pesquisa em performance como uma área em que se trata de música, mas que não pode ignorar a maneira como as pessoas percebem e reagem a essa música. As relações que se estabelecem entre todos os participantes da performance mostram-se relevantes. 


\section{Antropologia da Performance}

$\mathrm{Na}$ construção de uma área interdisciplinar, entre artes performáticas e ciências sociais, o diretor norte-americano de teatro e teórico da performance Richard Schechner, desenvolveu boa parte de seu pensamento, em parceria com o antropólogo escocês Victor Turner. Juntos, diretor de teatro e antropólogo desenvolveram as bases do que se chama Antropologia da Performance. Sobre essa parceria, Dawsey relata:

Um dos momentos mais expressivos para se pensar 0 surgimento da antropologia da performance ocorre nos anos de 1960 e 1970, quando Richard Schechner, um diretor de teatro virando antropólogo, faz a sua aprendizagem antropológica com Victor Turner, um antropólogo que, na sua relação com Schechner, torna-se aprendiz de teatro (DAUSEY, 2006, p. 17).

A aproximação entre Artes Performáticas e Antropologia, na visão Schechner, seria inevitável:

Quer os praticantes e acadêmicos de ambas as disciplinas gostem ou não, há pontos de contato entre a antropologia e o teatro: e provavelmente há mais pontos surgindo. Estes pontos de contato são até o momento seletivos - apenas um pouco da antropologia toca um pouco do teatro. Mas quantidade não é a única, ou mesmo a mais importante, medida de fertilidade conceitual. Esta mistura vai, penso eu, ser frutífera (SCHECHNER, 1985; FIORI, 2011).

Em sua argumentação, Schechner destacou seis pontos de contato entre Antropologia e Teatro. Embora o autor se refira ao teatro de maneira específica, não é difícil perceber que a aproximação com a Antropologia se estende às artes performáticas em geral, incluindo a Música. $\bigcirc$ próprio autor utiliza exemplos das diferentes áreas artísticas em sua argumentação. Sem aprofundar o assunto, seguem os seis pontos de contato entre Artes Performáticas e Antropologia levantados pelo diretor de teatro (Schechner, 1985; Fiori, 2011): 
1. Transformação do Ser e/ou da Consciência;

2. Intensidade da performance;

3. Interações entre audiência e performer;

4. A sequência da performance;

5. A transmissão do conhecimento performático;

6. Como as performances são geradas e avaliadas.

Recentemente, Schechner "revisita" esses pontos de contato entra as Artes Performativas e a Antropologia, afirmando que ainda são válidos e que, além disso, "esses pontos de contato não existem isoladamente. Estão entrelaçados uns com os outros, refletindo-se e interagindo uns com os outros" (SCHECHNER, 20 13, p. 39). Ao estabelecer a aproximação entre essas duas áreas do conhecimento, os autores da Antropologia da Performance desenvolveram conceitos que ajudam a compreender alguns fenômenos performáticos. Dentre esses, os conceitos de "liminaridade" e "communitas" contribuem para entender como as pessoas se relacionam durante uma performance.

\subsection{Liminaridade, liminóides e Communitas}

entendimento da Música enquanto Arte Performática e sua aproximação com a Antropologia da Performance requer a compreensão de alguns conceitos relacionados ao estudo dos rituais. Esses conceitos ajudam a enxergar, por exemplo, a apresentação de um quarteto de cordas em um teatro de São Paulo como um ritual estético. Segundo Wilson,

os homens expressam no ritual aquilo que os toca mais intensamente e, sendo a forma de expressão convencional e obrigatória, os valores dos grupos é que são revelados. Vejo no estudo dos ritos a chave para compreender-se a constituição essencial das sociedades humanas (UILSON, 1954 apud TURNER, 1974). 
Na obra O processo Ritual (TURNER, 1974), Turner desenvolve o conceito de liminaridade do ritual. Segundo Turner, Gennep ( 1960) mostra que os ritos de passagem' caracterizam-se por três fases: separação, margem (ou limen, significando "limiar" em latim) e agregação. A fase da separação significa o afastamento do indivíduo ou de um grupo de um ponto fixo anterior na estrutura social e/ou de um conjunto de condições sociais. Durante o período "limiar", as características do sujeito ritual são ambíguas. E na fase de agregação, consuma-se a passagem. É baseado na fase "limiar" dos ritos de passagem, apresentada por Cennep, que Turner desenvolve o conceito de liminaridade.

Segundo Turner, a liminaridade é o momento do ritual em que uma nova realidade é construída à margem da estrutura social. Sendo assim, "as entidades liminares não se situam aqui nem lá; estão no meio e entre as posições atribuídas e ordenadas pela lei, pelos costumes, convenções e cerimonial" (TURNER, 1974, p. 117).

É necessário observar que o conceito de liminaridade desenvolvido por Turner está relacionado a sociedades de pequena escala, ditas "tribais", onde o aspecto lúdico encontra-se intimamente ligado com o mundo do trabalho e da coletividade. Para Turner (TURNER, 1982), em contraposição ao fenômeno "liminal", as inovações técnicas surgidas nas sociedades complexas pós-industriais configurariam produtos "liminóides". Sobre isso, Cirino acrescenta:

- liminóide é um fenômeno semelhante ao liminar, porém sem ser idêntico a ele, e possui a característica de ser independente e crítico em relação à sociedade que o produz. [...] as ações liminóides também possuem o caráter de trabalho (para o indivíduo), porém realizadas num "tempo livre" (para a coletividade). Nos fenômenos liminóides, encontram-se as produções independentes, extraordinárias e críticas em relação à própria sociedade que as produz. (CIRINO, 2010, p. 225)

Outro conceito desenvolvido por Turner em seu $O$ Processo Ritual é o de "communitas". Segundo o antropólogo, "communitas" é um modelo de correlacionamento humano, que surge de maneira evidente

I Arnold van Gennep definiu os rites de passage como "ritos que acompanham toda mudança de lugar, estado, posição social de idade" (Gennep, 1960 apud Turner, 1974). 
no período liminar. Para Turner, é como se houvesse dois modelos de correlacionamento humanos, justapostos e alternantes: o da sociedade tomada como um sistema estruturado; e outro, o da sociedade considerada como um "comitatus" não estruturado, ou rudimentarmente estruturado. Este segundo modelo seria o equivalente a uma comunidade de "indivíduos iguais que se submetem em conjunto à autoridade geral dos anciãos rituais" (TURNER, 1974, p. 119):

Prefiro a palavra latina communitas à comunidade, para que se possa distinguir esta modalidade de relação social de uma "área de vida em comum". A distinção entre estrutura e "communitas" não é apenas a distinção familiar entre "mundano" e "sagrado", ou a existente por exemplo entre política e religião (Idem).

Ao descrever a "communitas", Turner relata um sentimento de "homogeneidade" e "camaradagem":

Assistimos a um momento situado dentro e fora do tempo, dentro e fora da estrutura social profana, que revela, embora efemeramente, certo reconhecimento (no símbolo, quando não mesmo na linguagem) de um vínculo social generalizado que deixou de existir, e contudo simultaneamente tem de ser fragmentado em uma multiplicidade de laços estruturais (TURNER, 1974, P. 118).

É preciso deixar claro que a dualidade "estrutura" e "communitas" não deve ser entendida como dois opostos, mas como complementares:

[...] não se trata simplesmente de dar um cunho geral de legitimidade às posições estruturais de uma sociedade. É antes uma questão de reconhecer um laço humano essencial e genérico, sem o qual não poderia haver sociedade. A liminaridade implica que o alto não poderia ser alto sem que o baixo existisse, e quem está no alto deve experimentar o que significa estar em baixo (TURNER, 1974, p. 119. Grifo no original). 
[...] A "communitas" sem estrutura pode unir e manter as pessoas juntas apenas momentaneamente (TURNER, 1974, p. 186).

Em relação à communitas, vale a pena citar a observação feita por Dawsey: "A sacada de Turner foi ver como as próprias sociedades sacaneiam-se a si mesmas, brincando com o perigo, e suscitando efeitos de paralisia em relação ao fluxo da vida cotidiana. Isso através de ritos, cultos, festas, carnavais, música, dança, teatro, procissões, rebeliões e outras formas expressivas (DAUUSEY, 2005).

estudo da performance musical deve compreender a maneira como as pessoas se relacionam durante essa performance. Ainda assim, vale a pena ressaltar que essa é uma área interdisciplinar que ainda está buscando seu espaço. Obviamente, não é possivel desprezar - conhecimento musicológico e a necessidade de se aprofundar nos estudos sobre teoria musical, conhecimentos técnicos, históricos, pedagógicos, etc. Apenas se faz necessário compreender que a performance é um fenômeno - "irredutivelmente" - social. A performance não envolve, somente, os músicos. Ela envolve a plateia, os espaços de performance, os funcionários desses espaços, enfim, tudo e todos que, de alguma forma, contribuem para a realização de uma apresentação musical. Nesse sentido, portanto, o estudo da performance musical pode e deve se valer do conhecimento das Ciências Sociais e, nesse sentido, os conceitos da Antropologia da Performance apresentados auxiliam o pesquisador a compreender o fenômeno estudado.

\section{Musicar: mu.si.car vtd}

Todos os estudiosos da performance musical citados acima concordam com a ideia de que o fazer musical transcende o trabalho do instrumentista executar as notas certas no momento certo. Esses estudiosos colocam, cada um à sua maneira, que a performance musical corresponde a uma atividade complexa e coletiva, resultado da participação de diversas pessoas, seja na preparação da performance, durante o acontecimento musical ou, até mesmo, após a apresentação. Seguindo essa linha de raciocínio, o musicólogo Christopher Small vai além, chegando a propor um novo significado para a palavra em inglês "music": 
Se existe alguma coisa que é clara sobre apresentar e ouvir [música] é que essas são ações, são algo que as pessoas fazem. Como eu pensei sobre isso, percebi que se a música não é uma coisa, mas uma ação, então, a palavra "música" [music] não deve ser apenas um substantivo. Deve ser um verbo - o verbo 'musicar' [to music]. Não apenas para expressar a idéia de performance - já temos verbos para isso -, mas para expressar a idéia muito mais ampla que é tomar parte em uma performance musical (SMALL, 2006, p. 12).

Ao propor que a música seja pensada como um verbo (to music) em vez de um substantivo (music), Small não está, simplesmente, acrescentando mais uma palavra ao dicionário. $\bigcirc$ que o autor propõe é que as pessoas passem a compreender música de maneira diferente. Para ele, pensar música enquanto um objeto (um substantivo) acarreta em algumas consequências (SMALL, 1998, p. 5). A primeira consequência é que a performance musical é colocada como algo que não faz parte do processo criativo, sendo apenas um meio pelo qual o trabalho isolado e independente do compositor utiliza para atingir o ouvinte. Nesse sentido, a performance é colocada como um sistema de comunicação de mão única, do compositor para o ouvinte, sugerindo que a tarefa do ouvinte seria, simplesmente, contemplar o trabalho e tentar entende-lo, sem contribuir com alguma interpretação. Isso seria negócio para o compositor. Outra consequência seria que, estando subordinada à composição, não seria possível a uma performance ser reconhecida como superior à obra que está sendo tocada. Na prática, o que se verifica é que uma composição simples em sua estrutura pode se transformar em uma grande performance. No caso do jazz, por exemplo, essa afirmação se mostra especialmente verdadeira, pois uma composição simples e conhecida (um Standard de jazz) é colocada à disposição dos instrumentistas para que esses a interpretem à sua maneira. Small ainda aponta para uma outra consequência do entendimento da música como um substantivo, que é a autonomia da obra musical. Isso levaria as pessoas a pensarem que a música existe sem uma necessária referência a uma ocasião, um ritual ou um contexto religioso, político ou de crenças sociais. Aqui, é possível estabelecer uma conexão com os conceitos da Antropologia da Performance apresentados anteriormente, onde a performance musical é entendida como um ritual estético. 
O entendimento de que música é um substantivo transforma a música em um "objeto", representado pela obra musical. Essa visão coloca o processo (a performance) como algo subordinado ao produto (COOK, 2006), enquanto que, para Small, ocorre exatamente o inverso: "a performance não existe para apresentar obras musicais, mas, ao contrário, obras musicais existem para fornecer aos performers algo para se apresentarem (SMALL, 1998, p. 8. Grifo no original). Assim, como alternativa ao substantivo, Small propõe o verbo "musicar" como uma maneira diferente de compreensão do que é música (no caso, "fazer música", "musicar"). Para o autor, a performance musical é algo muito mais rico e complexo do que, simplesmente, concentrar a atenção exclusivamente na obra musical e nos seus efeitos sobre um ouvinte. Ao ampliar a atenção para todo o grupo de relações que constituem uma performance, percebe-se que os principais significados musicais não são individuais, mas sociais. Ainda assim, Small faz questão de destacar que "esses significados sociais não devem ser enquadrados em algo chamado de 'sociologia' da música, que é separado dos significados dos sons, mas são fundamentais para uma compreensão da atividade que é chamada de música" (SMALL, 1998, p. 8). Desse modo, Small propõe o seguinte significado para o verbo "musicar" ("musicking"): "Musicar: é fazer parte, em qualquer função, de uma performance musical, seja através da interpretação, do ouvir, do ensaiar ou praticar, do fornecer o material para a performance (o que é chamado de composição), ou do dançar" (SMALL, 1998, p. 8).

É importante observar que, ao definir e propor o uso do verbo musicar, Small não faz distinção entre o que os intérpretes/instrumentistas fazem e o que os outros participantes da performance estão fazendo. Obviamente, o autor reconhece a diferença entre o trabalho de um instrumentista e o de um faxineiro que limpar o palco para a apresentação. Mas ele argumenta que existem palavras adequadas, capazes de esclarecer as diferenças entre essas duas atividades. Por outro lado, o uso do verbo "musicar" levaria as pessoas a se lembrarem de que as mais diferentes atividades se somam para realizar um único evento. Desse modo, compor, estudar, ensaiar, apresentar e ouvir não são processos separados, mas são aspectos de uma única atividade humana, denominada "musicar" (musicking) (SMALL, 1998, p. 1 1). Na visão de Small: 
ato de musicar estabelece, no lugar em que está acontecendo, um conjunto de relações e é nessas relações que se encontra o significado do ato. [...]

As relações de uma performance musical são enormemente complexas. Tão complexas, em última instância, para serem expressas em palavras. Mas isso não significa que elas sejam complexas demais para que nossa mente compreenda. $\bigcirc$ ato de musicar, em sua totalidade, proporciona uma linguagem de significados onde nós podemos compreender e articular essas relações e, por meio delas, compreender as relações de nossas vidas. (SMALL, 1998, p. 13)

\section{Considerações Finais}

$\bigcirc$ presente artigo constrói uma alternativa para o estudo da performance musical. A partir do diagnóstico feito por Cook, de que a performance musical é um fenômeno social, a etnomusicologia se apresenta como um caminho viável para a investigação desse fenômeno.

Seguindo essa linha de raciocínio, a Antropologia Musical proposta por Seeger é apresentada como uma maneira de pensar música. Sob essa perspectiva, a definição de música compreende a dimensão social da performance. Além disso, ao propor uma Antropologia Musical, em vez de uma Antropologia da Música, Seeger reconhece a necessidade de enfatizar as relações sonoras, a observação dos sons, e como essas contribuem para criar aspectos sociais.

Além disso, com o intuito de aprofundar essa questão, alguns conceitos da Antropologia da Performance também foram colocados. Baseado nos conceitos de "liminaridade" e de "communitas", é possível abordar uma performance musical de maneira semelhante a um ritual (um ritual estético) e, com isso, compreender como são construídas as relações entre os participantes da performance.

Por último, foi apresentado o conceito de "musicar", elaborado por Small. Ao propor um novo significado para o termo music, Small reforça a ideia de Cook de que o processo não deve ser entendido 
como subordinado ao produto. Para Small, a palavra "music" não deve ser entendida como um substantivo (produto), e sim como um verbo (processo). Dessa forma, o musicar envolveria outros participantes além dos músicos. Musicar, enfim, é engajar-se num processo interativo ligado à produção e vivencia da música.

Finalmente, o que se buscou foi a aproximação entre os conceitos elaborados por esses autores, que compreendem a performance musical como algo que está além da simples reprodução de uma partitura. Essa aproximação deve ser entendida como um caminho possivel para a pesquisa em Música, especialmente para o entendimento de diferentes práticas musicais, a partir de uma nova maneira de se pensar música. Como colocado por Cook, os estudos etnomusicológicos realizados nas últimas décadas do século XX já apresentam o entendimento da música em seus múltiplos contextos culturais, abrangendo a produção, a performance, a recepção e todas as outras atividades em virtude da qual a música é construída como uma prática cultural significativa. A "novidade" seria aproximar essa perspectiva dos estudos performáticos, da interpretação musical. $O$ caminho traçado neste trabalho tem essa finalidade. Ao entender a performance como um ritual, ao reconhecer a importância de outros participantes no processo de "musicar", novas alternativas se apresentam para a pesquisa em práticas interpretativas. 


\section{Referências}

CIRINO, G. Sobre as possibilidades de uma audição dialética. Ponto-e-vírgula, n. 8, 2010, p. 216-231; http://revistas.pucsp.br/index. php/pontoevirgula/article/view/13953, (05/11/2016).

COOK, N. Entre o processo e o produto: música elenquanto performance. Per Musi, Belo Horizonte, n. 14, 2006, p. 05-22.

We Are All (Ethno)musicologists Now. In: STOBART, Henry. The New (Ethno)musicologies. Toronto: The Scarecrow Press Inc, 2008, p. 48-70.

DAUUNSEY, J. C. Turner, Benjamin e Antropologia da Performance: $\bigcirc$ ligar olhado (e ouvido) das coisas. Campos - Revista de Antropologia Social, v. 7, n. 2, 2006, p. 17-25. http://ojs.c3sl.ufpr.br/ojs2/index.php/ campos/index.

Victor Turner e Antropologia da Experiência. Caderno de Campo, n. 13, 2005, p. 163-176.

CEERTZ, C. A interpretação das culturas. 1. ed., 13. reimpr. Rio de Janeiro: LTC, 2008.

CENNEP, A. V. The rites of passage. Trad. Monika B. Vizedom e Gabrielle L. Caffee. London: Routledge and Kegan Paul, 1960.

NEULIN, D. Schoenberg Remembered: Diaries and Recollections (1938-76). New York: Pendragon Press, 1980.

PINTO, T. O. Som e Música. Questões de uma Antropologia Sonora. Revista de Antropologia, v. 44, n. 1, p. 221-286. São Paulo: USP, 2001.

SCHECHNER, R. Points of contact between anthropological and theatrical thought. Between Theatre and Anthropology. University of Pennsylvania Press, 1985. Copyright Richard Schechner, reprinted with permission. First appeared in Between Theater and Anthropology 1985. University of Pennsylvania Press. Traduzido por FIORI, Ana L. de. Publicado em Cadernos de Campo, São Paulo, n. 20, 2011, p. 213-236.

SEECER, A. Why Suya sing: a musical anthropology of an Amazonian people. Originalmente publicado em 1987. Cambridge: Cambridge University Press, 2004. 
Etnografia da música. Cadernos de Campo. São Paulo, n. 17, 2008, p. 237-260. Trad. Giovanni Cirino. http://www.revistas.usp.br/ cadernosdecampo/article/viewFile/47695/5 I 433, (05/1 1/2016).

SMALL, C. Musicking: the meanings of performing and listening. Middletown: Wesleyan University Press, 1998.

TURNER, V. U. O processo ritual. Petrópolis: Vozes, 1974.

From Ritual to Theatre. The Human seriousness of Play. New York: PAJ Publications, 1982.

UILSON, Monica. Nyakyusa ritual and symbolism. American Anthropologist, v. 56, n. 2, p. 228-241, 1954.

\section{Sobre o autor}

Marcus V. S. R. De Almeida é Doutor em Música pela Universidade Estadual de Campinas - UNICAMP, dedica-se ao ensino, à pesquisa e à prática musical. Como educador, leciona no Colégio Dante Alighieri, onde é responsável pela Orquestra de Violões CDA. Como instrumentista (Guitarra e Violão), desenvolve trabalho autoral na área de Música Popular, tendo lançado o CD Nicwenra - guitar solo (2011). Como pesquisador, concluiu o Doutorado em 2016, depois de um estágio como pesquisador convidado na Queen's University of Belfast (Reino Unido) e o Mestrado em Performance em 2008, ambos pela UNICAMP.

Recebido em 08/11/2016 Aprovado em 02/09/2017 